\title{
Viola Allegranzi. « The Use of Persian in Monumental Epigraphy from Ghazni (Eleventh- Twelfth Centuries) »
}

\section{Sandra Aube}

\author{
(2) OpenEdition \\ Journals \\ Édition électronique \\ URL : http://journals.openedition.org/abstractairanica/42586 \\ DOI : 10.4000/abstractairanica.42586 \\ ISBN : 1961-960X \\ ISSN : 1961-960X \\ Éditeur : \\ CNRS (UMR 7528 Mondes iraniens et indiens), Éditions de l'IFRI
}

\section{Référence électronique}

Sandra Aube, «Viola Allegranzi. «The Use of Persian in Monumental Epigraphy from Ghazni (EleventhTwelfth Centuries) » », Abstracta Iranica [En ligne], Volume 37-38-39 | 2018, document 3, mis en ligne le 10 mars 2018, consulté le 02 octobre 2020. URL : http://journals.openedition.org/abstractairanica/ 42586 ; DOI : https://doi.org/10.4000/abstractairanica.42586

Ce document a été généré automatiquement le 2 octobre 2020.

Tous droits réservés 


\title{
Viola Allegranzi. « The Use of Persian in Monumental Epigraphy from Ghazni (Eleventh-Twelfth Centuries)»
}

\author{
Sandra Aube
}

\section{RÉFÉRENCE}

Viola Allegranzi. « The Use of Persian in Monumental Epigraphy from Ghazni (Eleventh-Twelfth Centuries) », Eurasian Studies 13 (2015), p. 23-41.

1 Le volume 13 de la revue Eurasian Studies réunit quatre articles résultant d'un panel sur le site de Ghazni (Afghanistan), donné à l'occasion du "Symposia Iranica - First Biennial Iranian Studies Graduate Conference" à l'université de St Andrews (avril 2013). Capitale ghaznévide (977-1186), puis ghoride, occupée dès la période bouddhique et jusqu'aux temps modernes, Ghazni avait fait l'objet d'investigations archéologiques entre 1957 et 1978 par la Mission Archéologique Italienne en Afghanistan. Depuis lors, l'accès au site est cependant devenu extrêmement limité. En s'appuyant sur les archives photographiques et sur le matériel collecté au cours de ces anciennes campagnes, Agnese Fusaro, Viola Allegranzi, Valentina Laviola et Martina Massullo, toutes membres du projet «Islamic Ghazni. An IsIAO Archaeological Project in Afghanistan » dirigé par Roberta Giunta (IsIAO/«L'Orientale », 2004-), offrent des données nouvelles et très attendues sur l'histoire de ce site d'envergure.

Dans le deuxième article de cette série, Viola Allegranzi s'intéresse aux inscriptions persanes de l'époque ghaznévide à Ghazni. Bien que la plupart des textes officiels et religieux étaient alors exécutés en arabe, plusieurs inscriptions attestent de l'emploi du persan dès cette période. Il s'agit d'inscriptions monumentales, souvent fragmentaires, provenant de tombes sculptées ou de revêtements architecturaux. Les plus anciens 
textes en persan qu'elle signale dans ce contexte sont sculptés dans le marbre et semblent provenir des monuments érigés sous le règne de Mahmūd (r. 388-421/998-1030) - aujourd'hui conservés dans un mausolée moderne à Rawza, à quelques kilomètres du site de Ghazni. Par une minutieuse et précise analyse des textes, de la paléographie, en questionnant la datation et la fonction originelle de ces inscriptions souvent fragmentaires, Allegranzi décrit le développement progressif de cette épigraphie persane à Ghazni depuis le début du XI ${ }^{\mathrm{e}}$ siècle. Elle fait apparaître une utilisation du persan très distincte de celle de l'arabe, puisque le persan se révèle être spécifiquement utilisé pour des textes poétiques.

On notera enfin la grande complémentarité entre les quatre articles sur Ghazni réunis dans ce volume, la dernière contribution - signée par Martina Massullo - prolongeant en partie l'étude d'Allegranzi, mais à la période post-médiévale.

\section{AUTEURS}

\section{SANDRA AUBE}

CNRS, Mondes iranien et indien, Paris 